\title{
Science Teacher Candidates' Learning and Studying Strategies in the Context of Self-regulation
}

\author{
Özkan Y1lmaz ${ }^{1}$ \\ ${ }^{1}$ Facutly of Education, Erzincan University, Erzincan, Turkey \\ Correspondence: Özkan Yılmaz, Eğitim Fakültesi, Erzincan Üniversitesi, Erzincan, Turkey
}

Received: June 19, 2017

Accepted: August 11, 2017

Online Published: August 17, 2017

doi:10.5430/ijhe.v6n4p161

URL: https://doi.org/10.5430/ijhe.v6n4p161

\begin{abstract}
This study investigated the students' individual study and learning strategies. Toward this purpose, open ended question form was administered to 40 university students who have enrolled department of mathematics and science education, faculty of education. Students were selected randomly in all level of class. Qualitative research method was used in the research. All data collection was gathered by personally-written document. Results showed that students use various strategies in learning and studying. But, some strategies are not primarily related to one of ten of the components of strategic learning. Educators must not assume that university students already have skills and habits; they should help and teach them.
\end{abstract}

Keywords: Learning strategy, Self-regulation, University student, Study skills

\section{Introduction}

In 21th century, the basic skill competencies and knowledge expectations changed when compared in the past for student. Today, student needs to have much more complex skills such as creative thinking, flexible problem solving, collaboration and innovativeness (PPRC, 2010). NCREL (2002) is apprised that new century skills need to considered in the context of academic standards. At that point, $21^{\text {th }}$ century learning includes: (1) digital-ages literacy, (2) effective communication, (3) Inventive thinking and (4) high productivity (NCREL, 2002). Developing those complex skills depend on adaptive capacity. Human beings are the only one organism who can learn new things and have adaptive capacity in the world (Hurd, 1998). In this context, cognitive is an important fact for learning and adaptiveness. As a learner, student needs to aware own cognition and have a skill for regulating it. At that point, self-regulation plays the crucial role understand and controlling person own learning (Schraw, Crippen, \& Hartley, 2006). Self-regulated learning theory is based on cognitive psychology and its origin start with the social-cognitive learning theory. The theory suggests that personal, environmental and behavioural factors are effective on learning. In the context of science education, self-regulation consists of three components: cognition, metacognition, and motivation (Schraw et al., 2006).

\subsection{Cognition}

The human brain is its ability to combine individual items in various ways. In other words, with different ways people can put the same experience together (Sousa, 2006). This experience is important to cognitive approach. Cognitive approach assumes that person's individual brings to new learning situations are one of the important factor in learning process (Woolfolk, Hughes, \& Walkup, 2008).

The cognitive component of self-regulation includes three subcomponents learning skills: cognitive strategies (simple strategies), problem solving strategies, and critical thinking skills. In the context of cognitive strategies, students use different individual tactics to improve their own learning (Schraw et al., 2006). Cognitive strategies are related to information processing in the learning. The main components of learning are the learner's prior knowledge, processes involved in perceiving and comprehending, and storing and retrieving information (Gredler, 2009). Problem solving strategies are much more complex than simple strategies. Problem solving is includes defining the current situation, a goal, and the specific operation or activities for reaching the goal (Woolfolk et al., 2008). The other complex strategy is the critical thinking. Critical thinking is related to a person capability to thinking reflectively and decide skillfully (Kong, 2015). 


\subsection{Metacognition}

Metacognition can be described as thinking about thinking or individual knowledge about cognition and strategy use (Gredler, 2009). There is a two key components of metacognition are (1) knowledge of cognition and (2) regulation of cognition. Knowledge of cognition refers to what ones know about own cognition and it includes subcomponents; declarative knowledge, procedural knowledge, and conditional knowledge (Schraw et al., 2006). Regulation of cognition also includes three components, planning, monitoring, and evaluation. Metacognitive strategies are principally not enough to promote achievement; person also must be motivated to use these strategies (Pintrich \& Groot, 1990).

\subsection{Motivation}

Motivation can be defined as what people desire, what they choose to do, and what they commit to do (Taheri, Louyeh, \& Hosseini, 2017). In other words, motivation is an internal state that arouses, directs and maintains behavior (Woolfolk et al., 2008). Motivation is not a simple subject. There are many theories which reflect different approaches to explain human thinking and behavior (Woolfolk et al., 2008). In the context of science education which is based on self-regulation theory motivation includes two important subcomponents, self-efficacy and epistemological beliefs (Schraw et al., 2006).

As can be seen on above, there are many factor and sub factor effective on self-regulation. At that point, it is hard to give a simple strategy for learner, to advance self-regulation and self-regulated learning. Furthermore, the level of knowledge and skills that each student has is not equal. There are individual differences in the way students study. These differences in study strategies are related to differences in achievement (McKeachie, 1988).

There are many factors and sub factor in self-regulation, also there are different students level. At that point, one major issue in self-regulation and self-regulated learning is related to assessment. End of the instruction and learning activities need to assess. Also, one's own learning activity need to assess. These assessments use for different purpose and give various information; such as prediction of academic performance, screening or criterion measures for study skills courses (Claire E. Weinstein, Zimmermann, \& Palmer, 1988).

\subsection{Assessing Learning Strategies: LASSI}

Every student has a special collection of talents, abilities and limitations (Woolfolk et al., 2008). High self-regulation is related to use these abilities in an effective way. There are two important factors in self-regulation. First, students need to know manipulate their cognitive process. To do so, students should learn how to control their own cognitive process during learning. There are some learnable techniques for selecting information, building internal connection among elements in the presented material, building between the new information and existing knowledge (Mayer, 1988). Second, successful implementation and evaluation of any learning strategies need to assess. These assessments requires for a reliable and valid means for measuring students' progress. It can be used to create personalized training. Also, it can be used to evaluate the effectiveness of that training (Claire E. Weinstein et al., 1988).

There are various instruments for assessing learning strategies. The most comprehensive scale is LASSI (Learning and Study Strategies Inventory). The LASSI scale has been used different purpose and adapted for many other populations. For instance, deaf students' success at college level (Albertini, Kelly, \& Matchett, 2012), at collage developmental students level (Deming, Valeri-Gold, \& Idleman, 1994), African American at precollege students level (Flowers, Bridges, \& Moore, 2012), university students' academic achievement (Taheri et al., 2017), Chinese version of the Learning and Study Strategies Inventory (Yip, 2013), Qatar; at university student level (Alkhateeb \& Nasser, 2014). In the early developmental stage of LASSI, 19 general categories were determined from survey of published study skills materials. First step, a preliminary pilot test was conducted and evaluated. The end of data analyze, the new set of potential LASSI was listed the 14 general categories (categories reduced from 19 to 14). Second step, the large number of revisions after the preliminary pilot test, a second pilot test was conducted. The number of items was reduced, and 10 scales measuring different clusters (reduced from14 to 10) of learning strategies and study attitudes were developed. These are anxiety $(\mathrm{r}=.81)$, attitude $(\mathrm{r}=.64)$, concentration $(\mathrm{r}=.80)$, information processing $(r=.79)$, motivation $(r=.79)$, scheduling $(r=.77)$, selecting main ideas $(r=.64)$, self-testing $(\mathrm{r}=.66)$, study aids $(\mathrm{r}=.70)$, test strategies $(\mathrm{r}=.79)$ (Claire E. Weinstein et al., 1988).

After $1^{\text {st }}$ edition of LASSI, around two decades later, $2^{\text {st }}$ edition was developed (Claire E Weinstein \& Palmer, 2002). There were some improvements in second edition. For instance, (1) created equal number of items for each scale (all of the scales contain eight items), (2) much more emphasis placed on the metacognitive concepts of awareness, reflection and self-regulation, (3) improved the psychometric properties...etc. There was no marginal change in the 
number of individual LASSI scales. Only, one of scale name was changed. Scheduling Scale replaced with called Time Management Scale. In $2^{\text {st }}$ edition, Individual LASSI scales were (1) anxiety $(r=.87)$, (2) attitude $(r=.77)$, (3) concentration $(\mathrm{r}=.86)$, (4) information processing $(\mathrm{r}=.84)$, (5) motivation $(\mathrm{r}=.84)$, (6) selecting main ideas $(\mathrm{r}$ $=.89)$, (7) self-testing $(\mathrm{r}=.84)$, (8) study aids $(\mathrm{r}=.73)$, (9) test strategies $(\mathrm{r}=.80)$, (10) time management $(\mathrm{r}=.85)$. With the second edition, individual LASSI scales reliability (Coefficient Alpha) was increased.

Fourteen years later, $3^{\text {st }}$ edition of LASSI was developed (Claire E Weinstein, Palmer, \& Acee, 2016). Some changes were made in the LASSI. For instance, each scale was comprised of 6 items as opposed to 8 items, Study Aids Scale replaced with a new scale called Using Academic Resources. There were no marginal changes in individual scale number. There was 10 scales likewise 2 st and $1^{\text {st }}$ edition. These scales were primarily related to one of the components of strategic learning: skill, will and self-regulation (Claire E Weinstein et al., 2016). In $3^{\text {th }}$ edition, Individual LASSI scales were (1) anxiety $(\mathrm{r}=.87)$, (2) attitude $(\mathrm{r}=.76)$, (3) concentration $(\mathrm{r}=.85)$, (4) information processing $(\mathrm{r}=.81)$, (5) motivation $(\mathrm{r}=.77)$, (6) selecting main ideas $(\mathrm{r}=.86)$, (7) self-testing $(\mathrm{r}=.80)$, (8) test strategies $(\mathrm{r}=.77)$, (9) time management $(\mathrm{r}=.80)$, (10) using academic resources $(\mathrm{r}=.76)$. In the third edition, individual LASSI scales reliability (Coefficient Alpha) was almost same with the second edition.

\subsection{Importance of LASSI in Self-regulation}

As was pointed out in the introduction to this paper, self-regulation was not a simple issue. It has many components that related to cognition, metacognition, and motivation. As regard LASSI to understand the importance for self-regulation, it needs a fairly detailed look at the structure of LASSI.

LASSI scale developmental work began in 1982. There were three editions which are developed over the time. In all versions have 10 scales measuring clusters. All these clusters are primarily related to one of three of the components of strategic learning: skill, will and self-regulation (Mayer, 1988; Claire E Weinstein \& Palmer, 2002; Claire E Weinstein et al., 2016).

\subsubsection{The Skill Component of Strategic Learning}

The first component information processing scale assess how well students identifying, acquiring and constructing meaning for new information in learning. The second component selecting main ideas scale assess students' thinking skills for identifying important information in any study activity. The other component test strategies scale assesses students' preparation and test taking strategies for any examination (Claire E Weinstein et al., 2016). As described above, in self-regulation, in the context of cognitive strategies, students use different individual tactics to improve their own learning. Cognitive strategies are related to information processing in the learning. As can be seen, the skill component of strategic learning in LASSI is related to self-regulation skills.

\subsubsection{The Will Component of Strategic Learning}

The first component anxiety assesses the degree of students' worrying about school and their academic performance. The second component attitude scale assesses students' attitudes and interests in college. The other component test motivation scale assesses students' willingness to exert the effort necessary to complete academic requirements (Claire E Weinstein et al., 2016). Motivation is one of important component for self-regulation. In LASSI scale, the will component (anxiety, attitude, motivation) for strategic learning is another related component for self-regulation.

\subsubsection{The Self-Regulation Component of Strategic Learning}

Third and the last component of LASSI scale, The Self-Regulation Component of Strategic Learning, is directly related to self-regulation and includes four sub-components. The first component concentration scale assesses students' ability to direct and maintain their attention on specific academic task. The second component self-testing scale assesses students' ability to use of comprehension monitoring techniques. The third component time management scale assesses students' use of time management principles for academic tasks. The fourth component using academic resource scale assesses students' willingness to use resource when they encounter any problems in study activities (Claire E Weinstein et al., 2016). As can be seen, all component LASSI scale is directly or indirectly related to self-regulation. So that LASSI can be use an instrument for assessing self-regulation skills.

In education and the behavioral science, it is hard to measure with appropriate degree of precision. The degree of accuracy is related to the purpose serving the measurement. In the behavioral and social sciences, variables can't be observed directly. So that uses indirect indicators from sample (Hopkins, 1998). There are various approaches to measuring any construct. But all assessment procedures have their own strengths and limitations. One assessment can produce highly reliable scores, at the same time cannot measure some aspects of a construct (Reynolds, Livingston, \& Willson, 2006). LASSI is a standardized scale and designed for measuring students' learning 
strategies by questionnaire form. Its strength is gathering information in short time with numerical way. So psychoeducational evaluation is much easier and objective. But every students have own learning strategy. If a student cannot find the own learning strategy item in questionnaire form, that student has no opportunity to present own used strategy. The instrument of self-reporting provides deeper information about the strategies. Contrary to LASSI, this research was used qualitative approach to explore what kinds of strategies using by science teacher candidates at undergraduate level. In this context, It was used the exploratory research. The results obtained with this study can be used as a supporter and developer data for new LASSI edition. And, it can contribute for a better understanding Learning Strategies and unveiling the complexity of an important dimension of self-regulated learning.

This study is aimed to reveal;

What kinds of learning and studying strategies use science teacher candidates in academic learning?

\section{Method}

\subsection{Research Design}

In researches, there are different types of phenomena which are needed to explain. There are different ways and measurements for explaining that phenomena. In quantitative research uses separate numerical measurement or manipulation of each construct in a set of constructs. On the other side, in qualitative research uses the study of a constellation of constructs (Viswanathan, 2005). LASSI scale is designed quantitative perspective. It has special items to measure special sub-constructs. The main construct is related to measuring learners' skills of learning and study strategies. Inventory respondent need to read items and specify the degree of participation in the expression with numerical way. And, there is no change to explain their own idea with words or sentences. Psychometric tests are aims to measure human personality and ability characteristics. And, they can suffer from cultural content bias (Coolican, 1994). At that point, It can be considered that every learner can has an own learning strategy.

This study used a qualitative research method to answer research question. Qualitative research is flowing from philosophical assumptions. It uses interpretive perspective and procedures involved in studying social or human problems (Creswell \& Poth, 2017).

Students were answered the 10 question about what kind of strategies used in learning and study in the frame of LASSI structure. And, the personally-written document used to learn students' strategies.

\subsection{Participants}

Open ended questions asked to 40 university students who are enrolled department of mathematics and science education, faculty of education which is placed east part of Turkey. Participants were selected randomly in all level of class. Students did not answer demographic questions (such as gender, age, level...etc.) which were placed in the form. Therefore, there was no gather detailed information about the participants.

\subsection{Instruments}

Open ended question form prepared for gathering strategies which are used by students. This form included 10 questions which are based on LASSI structure. These questions are (1) imagine that you have schoolwork or a project. How do you control your excitement and anxiety? How do you control your concentration? (2) How do you maintaining positive attitudes in school and interest in performing the tasks related to school success? (3) Imagine that you have a task such as reading, writing, listening...etc. How do you ensure your attention and concentration? (4) Imagine that you have to learn a new subject. And later, It would be asked to you some question about that subject. What do you do for learning that subject? (5) How do you motivate yourself to daily works (6) How do you test yourself what you know about a topic that you have learned before? (7) Imagine that you have a task such as reading, writing or listening. How do you emphasize the main idea? (8) You have to learn a new topic. How do you use resources (books, newspapers, magazines, journals, internet...etc.) for learning that new topic? (9) How to you manage your time for academic success. What do you do for that? (10) Imagine that you have an exam in coming days. How do you study for that exam, what do you do?

\subsection{Data Collection}

Data collection was gathered by personally-written document. The document was included 10 open-ended questions. Students were answered those questions with no time limit. They wrote their thoughts comfortably. 


\subsection{Data Analysis}

In this research, qualitative research method was used. All data collected from the participants were written expressions which were collected 10 sub-topics. Nvivo PC software was used to organize and present the data. Ten questions were associated with ten themes (see Table 1).

Table 1 . Themes and questions

\begin{tabular}{|c|c|}
\hline Themes & Questions \\
\hline Excitement and anxiety control & $\begin{array}{l}\text { Imagine that you have schoolwork or a project. How do you control } \\
\text { your excitement and anxiety? }\end{array}$ \\
\hline $\begin{array}{l}\text { Maintain a positive attitude } \\
\text { towards a situation }\end{array}$ & $\begin{array}{l}\text { How do you maintaining positive attitudes in school and interest in } \\
\text { performing the tasks related to school success. }\end{array}$ \\
\hline Attention and concentration & $\begin{array}{l}\text { Imagine that you have a task such as reading, writing, listening... etc. } \\
\text { How do you ensure your attention and concentration? }\end{array}$ \\
\hline $\begin{array}{l}\text { Access To Information and } \\
\text { Information Processing }\end{array}$ & $\begin{array}{l}\text { Imagine that you have to learn a new subject. And later, It would be } \\
\text { asked to you some question about that subject. What do you do for } \\
\text { learning that subject? }\end{array}$ \\
\hline Motivation & How do you Motivate Yourself to daily works \\
\hline Self-testing & $\begin{array}{l}\text { How do you test yourself what you know about a topic that you have } \\
\text { learned before? }\end{array}$ \\
\hline Selecting main ideas & $\begin{array}{l}\text { Imagine that you have a task such as reading, writing or listening. } \\
\text { How do you emphasize the main idea }\end{array}$ \\
\hline Study aids & $\begin{array}{l}\text { Imagine that you have a task such as reading, writing or listening. } \\
\text { How do you emphasize the main idea }\end{array}$ \\
\hline Time management & $\begin{array}{l}\text { How to you manage your time for academic success. What do you do } \\
\text { for that? }\end{array}$ \\
\hline Test strategies & $\begin{array}{l}\text { Imagine that you have an exam in coming days. How do you study } \\
\text { for that exam, what do you do before, and in the exam? }\end{array}$ \\
\hline
\end{tabular}

As seen on Table1, all qualitative data collected via written documents were categorized ten themes. Every theme was illustrated diagrams.

\section{Results and Discussion}

In order to understand what kind of strategies student use in learning and studying, personal-written documents were analyzed. Analyzing showed that strategies preferred by students were collected 10 themes and 73 different strategies. These themes were presented below with figures.

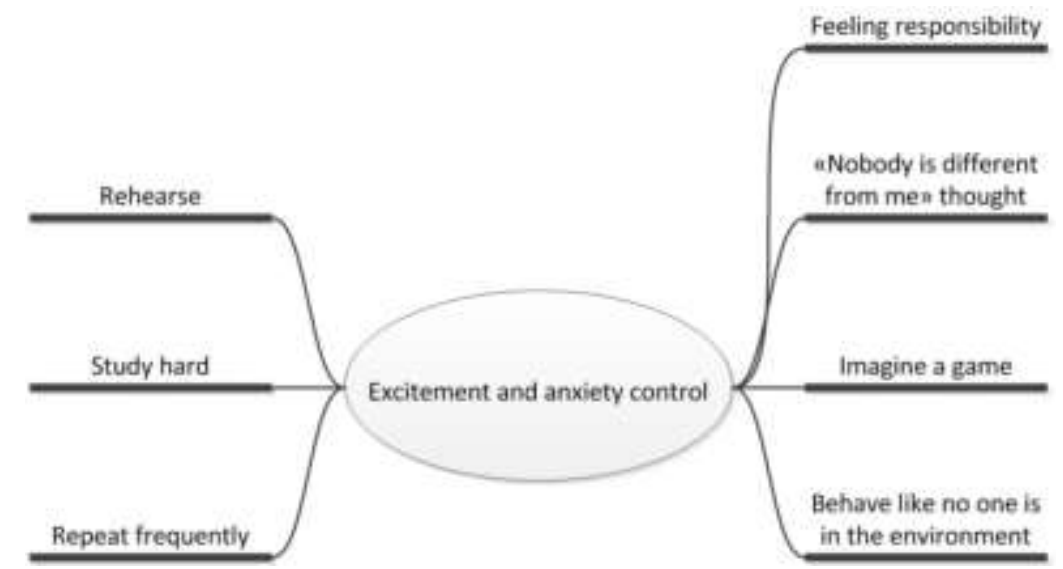

Figure 1. Excitement and anxiety control 
Figure 1 shows the excitement and anxiety control strategies used by students. There are seven strategies students use to control their own anxiety. Anxiety addresses the degree of students worrying about school work. It depends on their performance in school (Eldredge, 1990). In the $1^{\text {st }}$ version of LASSI scale, anxiety scale has contained 10 items (Claire E. Weinstein et al., 1988). In the 2nd version, anxiety scale has contained 8 items and the last 3th version of scale contained only 6 items (Claire E Weinstein \& Palmer, 2002; Claire E Weinstein et al., 2016). In the present study, it was found that students use 7 different strategies for anxiety control. But, all these strategies are not properly suitable to reduce or control anxiety. Gall, Gall, Jacobsen, and Bullock (1990) stated that "students should to learn how to control anxiety, rather than trying to ignore it." As seen on figure 1, "Behave like no one is in the environment" or "Nobody is different from me though" are not kind of control strategies. It is an escape-avoidance behavior. In this regard, it could be said that students don't know much more excitement and anxiety control strategies.

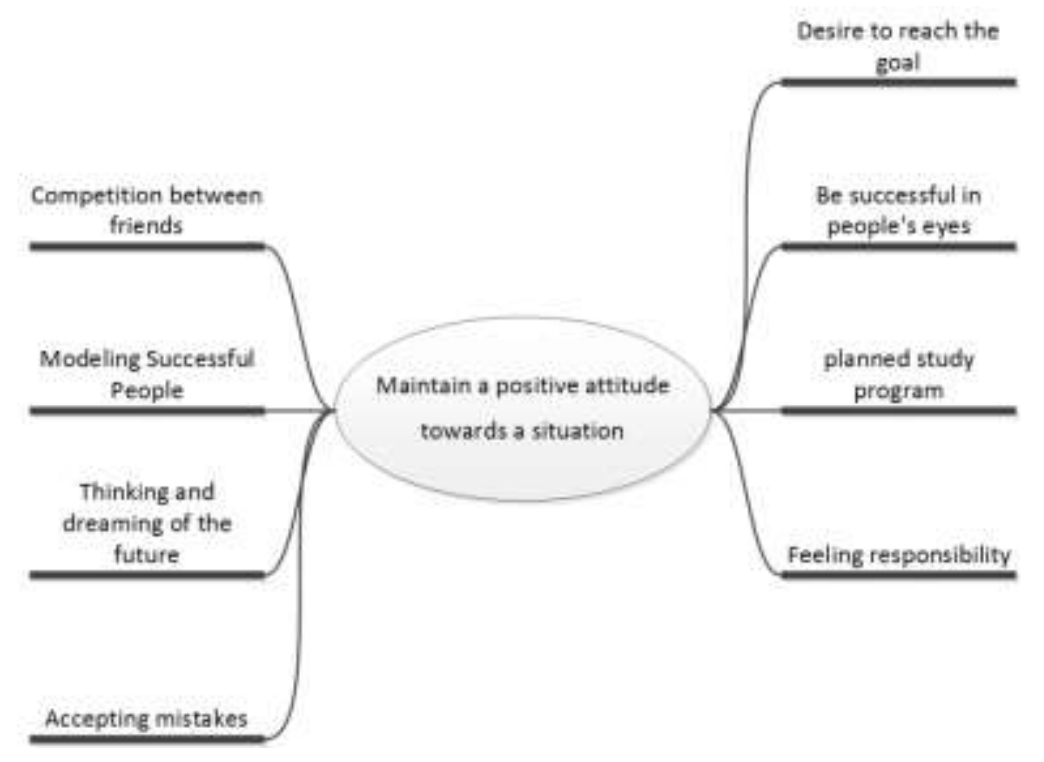

Figure 2. Maintain a positive attitude towards a situation

As can be seen from the figure 2 there are eight strategies students use to maintain a positive attitude towards a situation. Attitude scale is used for assessing whether or not students have educational goals (Eldredge, 1990). In the 1st version of LASSI scale, attitude scale has contained only 4 items (Claire E. Weinstein et al., 1988). In the 2nd version, attitude scale has contained 8 items and the last 3th version of scale contained 6 items (Claire E Weinstein \& Palmer, 2002; Claire E Weinstein et al., 2016). In the present study, it was found that students use 8 different strategies for maintain a positive attitude. There is a tight linkage between attitude and behavior. One approach asserts that attitudes determine behavior. Socially, attitude is a cognitive factor which is regulates human motivation and action. (Bandura, 1997). Taking responsibility and positive thinking are two important elements for maintaining a positive attitude (Fabrega, 2017). And, good problem solvers focus on positive aspect (Gall et al., 1990). As seen in figure 2, "feeling responsibility" and "desire reach the goal" are two mainly important approaches to positive attitudes. The other students' approaches are can be seen as special and changeable student to student. 


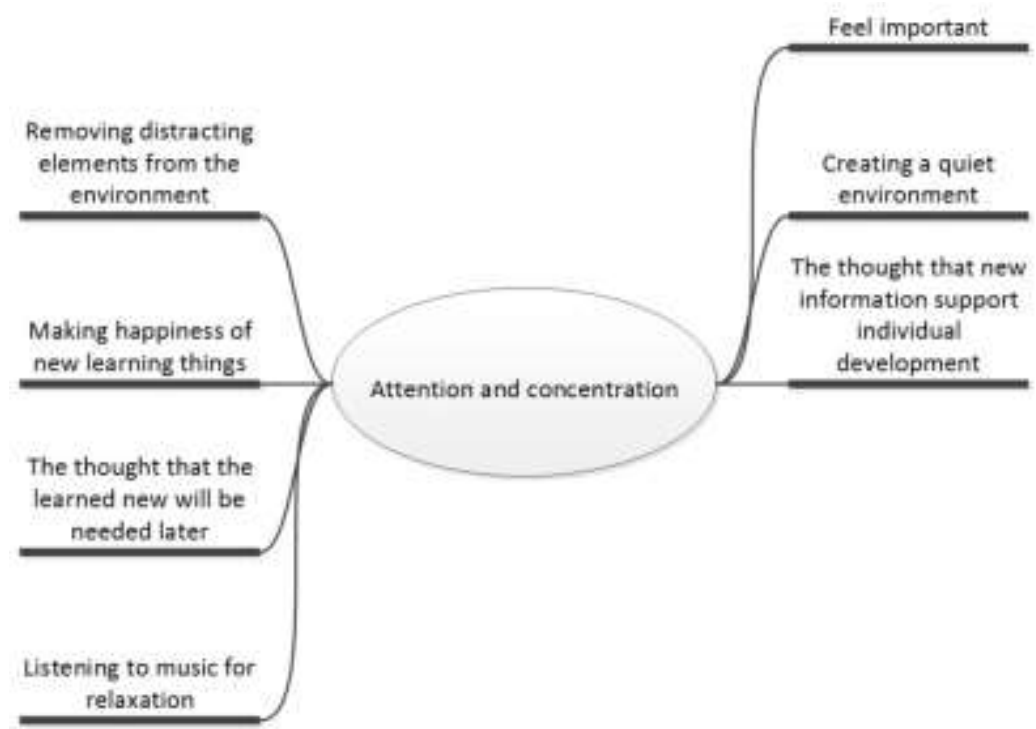

Figure 3. Attention and concentration

It can be seen from the figure 3 there are seven strategies students use to control of attention and concentration. Attention and concentration scale focus on students' ability to pay close attention to learning task.(Eldredge, 1990). In the 1st version of LASSI scale, attention and concentration scale has contained 8 items (Claire E. Weinstein et al., 1988). In the 2nd version, attention and concentration scale has contained 8 items and the last 3 th version of scale contained 6 items (Claire E Weinstein \& Palmer, 2002; Claire E Weinstein et al., 2016). In the present study, it was found that students use 7 different strategies for attention and concentration control. The brain processes many stimuli at any moment. Attention is selecting stimuli and ignoring others. To do so, we need to know that what we need to know and what we would like to know (Woolfolk et al., 2008). As seen in figure 3, students use two main approaches to keep attentions and concentration. First, they use internal regulation: making the happiness of new learning things, the thought that the learned new would be needed later, feel important, and the thought that new information supports individual development. Second, they use externals regulation: removing distracting elements from the environment, listening to music for relaxation, creating a quiet environment.

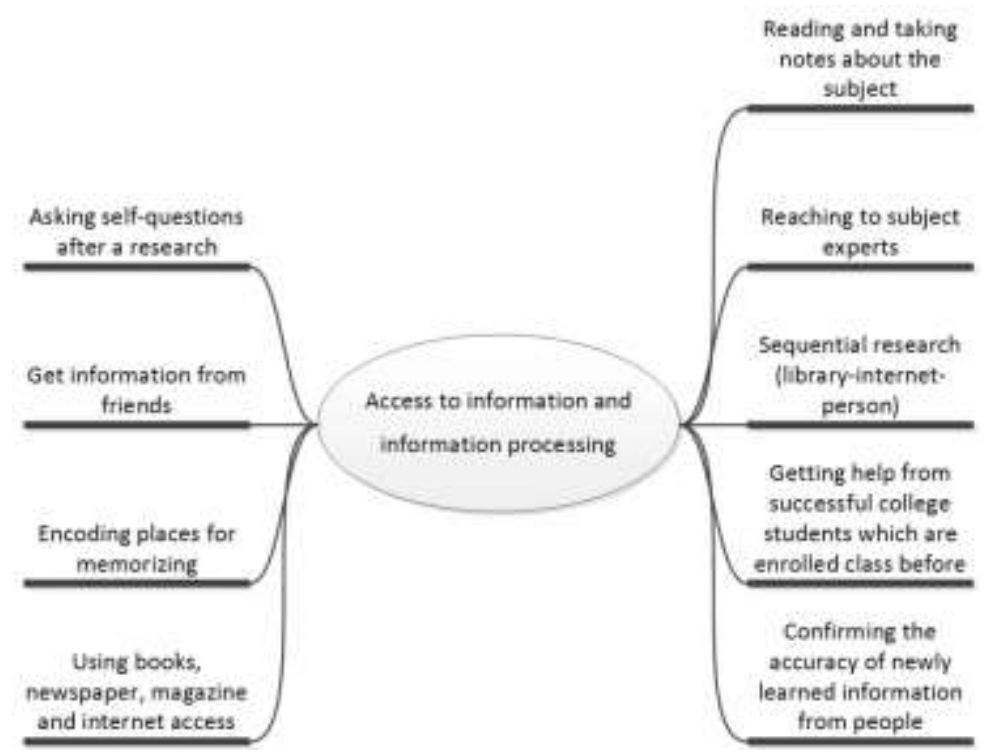

Figure 4. Access to information and information processing

From the Figure 4 above we can see that students use nine different strategies to access to information and information processing. Access to information and information processing scale focus on students' ability to access information and, use of mental imagery, verbal elaboration, comprehension monitoring, and reasoning (Eldredge, 1990). In the 1st version of LASSI scale, information processing scale has contained 17 items (Claire E. Weinstein et al., 1988). In the 2 nd version, information processing scale has contained 8 items and the last 3 th version of scale 
contained 6 items (Claire E Weinstein \& Palmer, 2002; Claire E Weinstein et al., 2016). In the present study, it was found that students use 9 different strategies for access to information and information processing. Information processing involves gathering information and organizing it in relation to what is already known. The human mind is taking information in, storing and using it (Woolfolk et al., 2008). At that point access to information is play critical role. There are many ways to get information (such as internet, library, friends...etc.). But, reliable information is important for learning. Therefore, students' ability to access to information and using information processing strategies play an important role in meaningful learning. As seen in figure 4, students use different approach to access information and information processing. It is not generalized for all students; all these can be used for creating imaginable and verbal elaborations, and the organizational scheme.

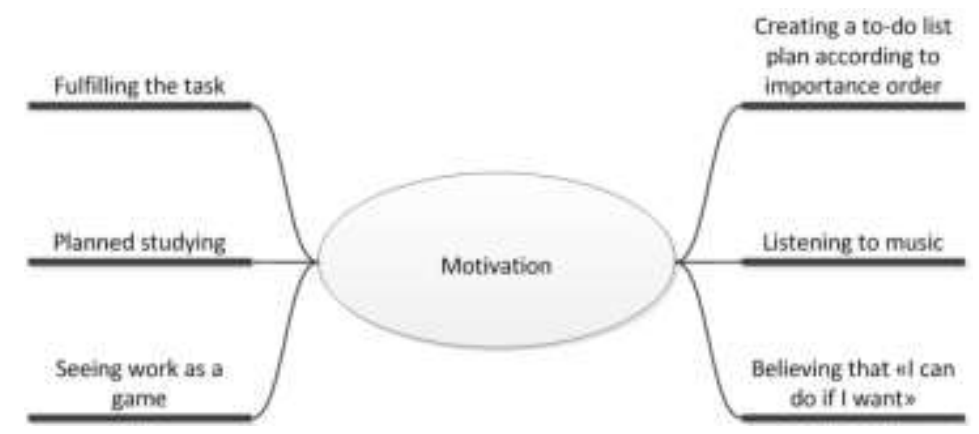

Figure 5. Motivation

The Figure 5 above illustrates students' motivational strategies. As can be seen students use six strategies to motivate them. Motivation is addressing students' diligence, self-discipline, and willingness to work hard (Eldredge, 1990). In the 1st version of LASSI scale, motivation scale has contained 14 items (Claire E. Weinstein et al., 1988). In the 2nd version, motivation scale has contained 8 items and the last 3th version of scale contained 6 items (Claire E Weinstein \& Palmer, 2002; Claire E Weinstein et al., 2016). In the present study, it was found that students use only 6 different strategies for motivation. With the perspective of motivation factors in students' approaches to learning, motivation is related to the amount of intellectual energy typically used in learning activities. Also, "motivation is affected by experiences of learning, as well as itself influencing the quantity and the quality of what is learned" (Entwistle, 1988). There are two important factors that motivate students to put effort into studying. (1) External factor; students study for external rewards or avoid punishments. (2) Internal factor; making casual attributions, developing expectations for success, and recalling positive models (Gall et al., 1990). As seen in figure 5, students use only six strategies to motivate themselves. All these are not exactly external or internal motivator elements. For instance, "seeing works as a game" or" listening to music" is not considered as motivator factor theoretically. These seem as relaxing methods. But students put forward these are their motivational strategies.

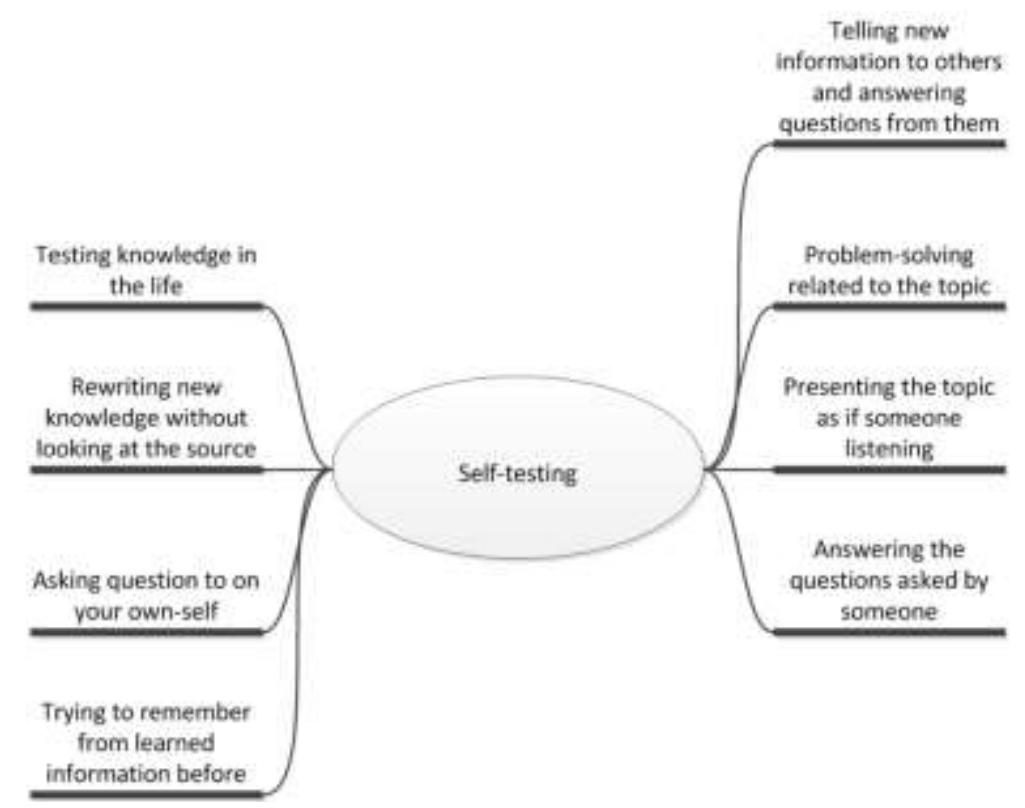

Figure 6. Self-testing 
From the Figure 6 above we can see that students use eight different strategies for self-testing. Self-testing is addressing whether students know how to approach different types of tests (Eldredge, 1990). In the 1st version of LASSI scale, self-testing scale has contained 5 items (Claire E. Weinstein et al., 1988). In the 2nd version, self-testing scale has contained 8 items and the last 3th version of scale contained 6 items (Claire E Weinstein \& Palmer, 2002; Claire E Weinstein et al., 2016). In the present study, it was found that students use 8 different strategies for self-testing. Self-testing encourages of deep processing and developing independent study skills. Self-questioning is much more useful than answering pre-prepared questions (Gall et al., 1990). As seen in figure 6, students use self-questioning and pre-prepared questions to improve their learning.

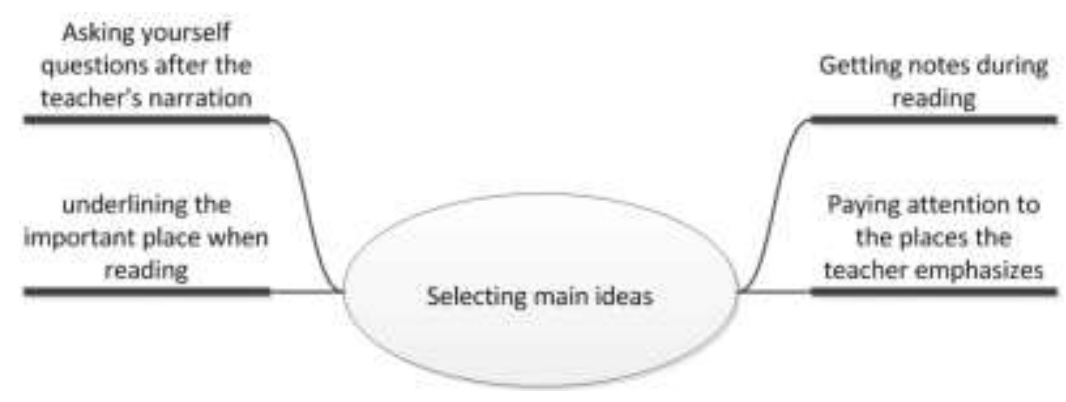

Figure 7. Selecting main ideas

It can be seen from the figure 7 there are four strategies students use to selecting main ideas when they have a reading or listening activity. Selecting main ideas is address students' ability to pick out important information for further study (Eldredge, 1990). In the 1st version of LASSI scale, selecting main ideas scale has contained only 4 items (Claire E. Weinstein et al., 1988). In the 2nd version, selecting main ideas scale has contained 8 items and the last 3th version of scale contained 6 items (Claire E Weinstein \& Palmer, 2002; Claire E Weinstein et al., 2016). In the present study, it was found that students use only 4 different strategies for selecting main ideas. An important academic task involves separating the important from unimportant (Claire E Weinstein et al., 2016). Without that skill, students should have much more time to study. As seen in figure 7, students use two kinds of strategy for reading activity and the others for listening activity. They know how to separate the important from the unimportant. But there are different strategies to main idea comprehension and these can be learned (Jitendra, Hoppes, \& Xin, 2000). The present study showed that they don't know other strategies or they use much more specific ones.

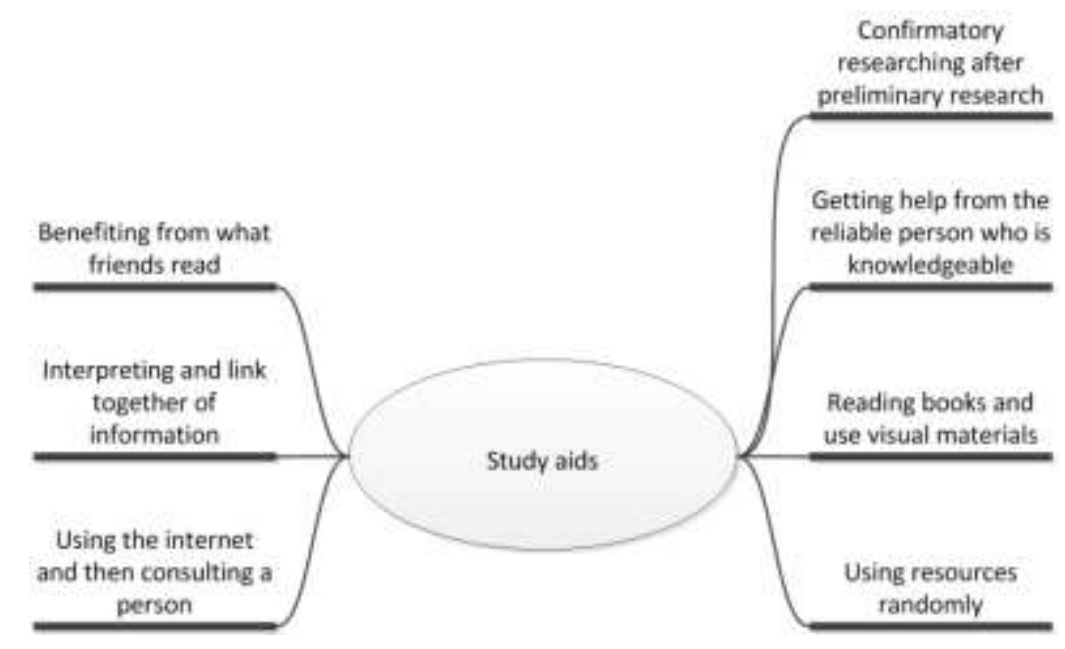

Figure 8 Study aids

It can be seen from the figure 8 students use seven strategies for study aids. Study aids scale is students create or support techniques or material to help their own them learn and remember information (Eldredge, 1990). In the 1st version of LASSI scale, study aids scale has contained 8 items (Claire E. Weinstein et al., 1988). In the 2nd version, study aids scale has contained 8 items and the last 3 th version of scale has no included that scale (Claire E Weinstein \& Palmer, 2002; Claire E Weinstein et al., 2016). In the present study, it was found that students use 7 different 
strategies for study aids. Students use the internet, friends and, reliable person to get aids, and use the visual material as supplementary.

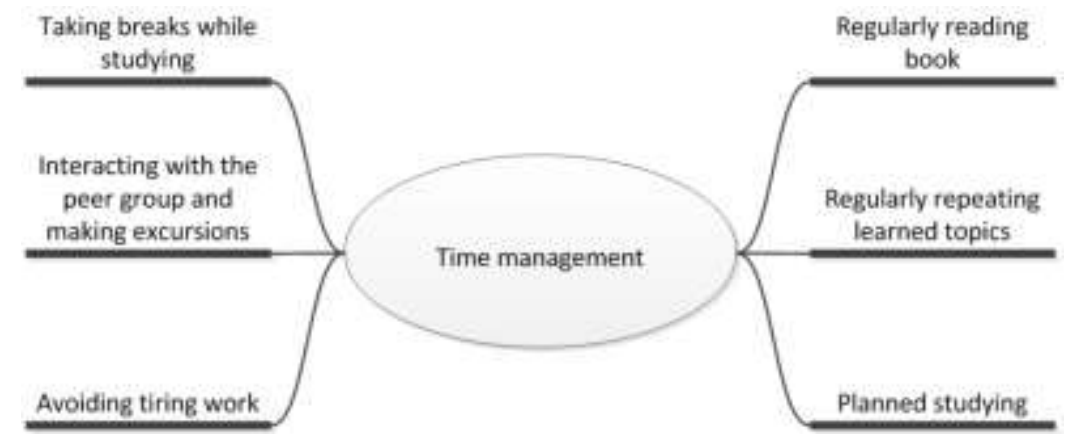

Figure 9 Time management

It can be seen from the figure 9 there are six strategies students use to time management. Time management is address students' ability to use of study schedules and other time management principles (Eldredge, 1990). In the 1st version of LASSI scale, time management scale name was "scheduling" has contained 5 items (Claire E. Weinstein et al., 1988). In the 2 nd version, time management scale has contained 8 items and the last 3 th version of scale contained 6 items (Claire E Weinstein \& Palmer, 2002; Claire E Weinstein et al., 2016). In the present study, it was found that students use 6 different strategies for time management. Loomis (2000) stated that 'Time Management was a very strong predictor of one's overall performance in this class'. Students should learn to manage time on their own and design how to allocate enough time to finish work(Gall et al., 1990). The present study showed that students did not use effective time management strategy (see figure 9; avoiding tiring work, interacting with the peer group and making excursions).

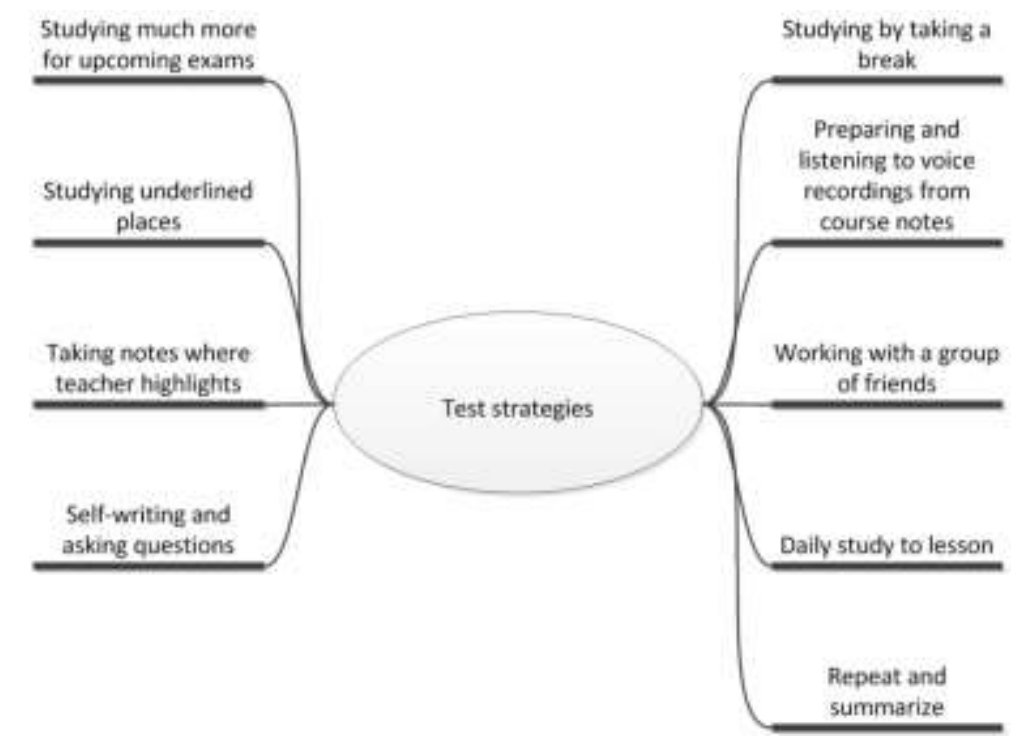

Figure 10. Test strategies

From the Figure 10 above we can see that students use nine different test strategies. Test strategies focus on if students knows how to approach different type of test questions (Eldredge, 1990). In the 1st version of LASSI scale, test strategies scale has contained 13 items (Claire E. Weinstein et al., 1988). In the 2nd version, test strategies scale has contained 8 items and the last 3th version of scale contained 6 items (Claire E Weinstein \& Palmer, 2002; Claire E Weinstein et al., 2016). In the present study, it was found that students use 9 different strategies for test strategies. Test strategies need in two place: preparing for the test and taking the test. Strategies can be used before the test, during the test, and both phases (Gall et al., 1990). As seen on figure 10, student use different test strategies. These strategies can be used only preparing for the test. It seems that students don't know or don't use other strategies much more. 


\section{Conclusion}

This study has attempted for providing an in-depth exploring what kind of learning strategies using by science teacher candidates at undergraduate level. In the frame of LASSI this study showed that students use different strategies changeable four to nine for every sub-scale. But, as seen in figures (above) some strategies are not primarily related to one of ten of the components of strategic learning. In some component, students don't use much more strategies for learning. Self- regulation (a specially self-regulated learning) is related to be students aware of how to act on learning tasks and their learning skills (Talbot, 1996). If students are not aware of different strategies, the academic programs should focus on how to teach their students to have better learning strategies (Jesús, Claudia, \& Rosalinda, 2015). Taheri et al. (2017), stated that teaching learning strategies to the students is one of the career priorities for the consultant teachers. At that point, it can be put forward that students know various strategies but need to learn specific strategies. Also, educators must not assume that university students already have skills and habits, they should teach them.

This study not aimed to compare the LASSI scales edition. However, these results can be used as a supplement for developing a new version of LASSI scales and so on.

\section{References}

Albertini, J. A., Kelly, R. R., \& Matchett, M. K. (2012). Personal Factors That Influence Deaf College Students' Academic Success. The Journal of Deaf Studies and Deaf Education, 17(1), 85-101. https://doi.org/10.1093/deafed/enr016

Alkhateeb, H. M., \& Nasser, R. (2014). Assessment of learning and study strategies of university students in qatar using an arabic transla- tion of the learning and study strategies inventory. Psychological Reports: Sociocultural Issues in Psychology, 114(3), 947-965. https://doi.org/10.2466/11.03.PR0.114k26w3

Bandura, A. (1997). Self-efficacy : the exercise of control. New York: W.H. Freeman.

Coolican, H. (1994). Research Methods And Statistics In Psychology (2 ed.): Hodder \& Stoughton.

Creswell, J. W., \& Poth, C. N. (2017). Qualitative Inquiry and Research Design: Choosing Among Five Approaches (4th. ed.). California: SAGE Publications Inc.

Deming, M. P., Valeri-Gold, M., \& Idleman, L. S. (1994). The reliability and validity of the learning and study strategies inventory (LASSI) with college developmental students. Reading Research and Instruction, 33(3), 309-318. https://doi.org/10.1080/19388079409558163

Eldredge, J. L. (1990). Learning and Study Strategies Inventory - High School Version (LASSI - HS). Journal of Reading, 34(2), 146-149.

Entwistle, N. (1988). Motivational Factors in Students' Approaches to Learning. In R. R. Schmeck (Ed.), Learning Strategies and Learning Styles (pp. 21-51). Boston, MA: Springer US. https://doi.org/10.1007/978-1-4899-2118-5_2

Fabrega, M. (2017). 21 Ways to Create and Maintain a Positive Attitude. Retrieved 13 July, 2017, from https://daringtolivefully.com/positive-attitude

Flowers, L. A., Bridges, B. K., \& Moore, J. L. (2012). Concurrent validity of the Learning and Study Strategies Inventory (LASSI): A study of African American precollege students. Journal of Black Studies, 43(2), 146-160. https://doi.org/10.1177/0021934711410881

Gall, M. D., Gall, J. P., Jacobsen, D. R., \& Bullock, T. L. (1990). Tools for Learning: A guide to teaching study skills. United States of America: Association for Supervision and Curriculum Development.

Gredler, M. E. (2009). Learning and instruction : theory into practice (6th ed.). Upper Saddle River, N.J.: Merrill Pearson.

Hopkins, K. D. (1998). Educational and psychological measurement and evaluation (8th ed.). Boston: Allyn \& Bacon.

Hurd, P. D. (1998). Scientific literacy: New minds for a changing world. Science Education, 82(3), 407-416. https://doi.org/10.1002/(SICI)1098-237X(199806)82:3<407::AID-SCE6>3.0.CO;2-G

Jesús, A. V. M. d., Claudia, D., \& Rosalinda, C. C. (2015). Academic progress depending on the skills and qualities of learning in students of a business school. The Turkish Online Journal of Educational Technology, 14(3), 1-8. 
Jitendra, A. K., Hoppes, M. K., \& Xin, Y. P. (2000). Enhancing Main Idea Comprehension for Students with Learning Problems. The Journal of Special Education, 34(3), 127-139. https://doi.org/10.1177/002246690003400302

Kong, S. C. (2015). An experience of a three-year study on the development of critical thinking skills in flipped secondary classrooms with pedagogical and technological support. Computers \& Education, 89, 16-31. https://doi.org/10.1016/j.compedu.2015.08.017

Loomis, K. D. (2000). Learning Styles and Asynchronous Learning: Comparing the LASSI Model to Class Performance. JALN, 3(1), 23-32.

Mayer, R. E. (1988). Learning Strategies: an overview. In C. E. Weinstein, E. T. Goetz \& P. A. Alexander (Eds.), Learning and Study Strategies: issues in assessment, instruction, and evaluation (pp. 11-22). San Diego, California 92101: Academic Press, Inc. https://doi.org/10.1016/B978-0-12-742460-6.50008-6

McKeachie, W. J. (1988). The need for study strategy training. In C. E. Weinstein, E. T. Goetz \& P. A. Alexander (Eds.), Learning and Study Strategies: issues in assessment, instruction, and evaluation (pp. 3-9). San Diego, California 92101: Academic Press, Inc. https://doi.org/10.1016/B978-0-12-742460-6.50007-4

NCREL. (2002). enGauge 21st Century Skills: Digital Literacies for a Digital Age. Retrieved 17 April, 2017, from http://files.eric.ed.gov/fulltext/ED463753.pdf

Pintrich, P. R., \& Groot, E. V. D. (1990). Motivational and self regulated learning components of classroom academic performance. Journal of Educational Psychology, 82(1), 33-40. https://doi.org/10.1037/0022-0663.82.1.33

PPRC. (2010). 21th Century Skills for Students and Teachers. Honolulu: Kamehameha Schools, Research \& Evaluation Division: Pasific Policy Research Center.

Reynolds, C. R., Livingston, R. B., \& Willson, V. (2006). Measurment and Assessment in Education. United States of America: Pearson Education, Inc.

Schraw, G., Crippen, K. J., \& Hartley, K. (2006). Promoting self-regulation in science education: Metacognition as part of a broader perspective on learning. Research in Science Education, 36(1-2), 111-139. https://doi.org/10.1007/s11165-005-3917-8

Sousa, D. A. (2006). How the Brain Learns. California: Corwin Press.

Taheri, M., Louyeh, A. A., \& Hosseini, N. (2017). Learning and study strategies inventory (LASSI) and its relationship with university students' academic achievement. International Online Journal of Education and Teaching (IOJET), 4(3), 246-257.

Talbot, G. L. (1996). Self-regulated learning, effort awareness and management in college students: Are they aware of how they act on learning tasks and their learning skills (pp. 35p.).

Viswanathan, M. (2005). Measurement Error and Research Design: SAGE Publications. https://doi.org/10.4135/9781412984935

Weinstein, C. E., \& Palmer, D. R. (2002). LASSI User's Manual: For Those Administering the Learning and Study Strategies Inventory (2th ed.): H \& H Pub.

Weinstein, C. E., Palmer, D. R., \& Acee, T. W. (2016). LASSI User's Manual: For Those Administering the Learning and Study Strategies Inventory (3th ed.): $\mathrm{H} \& \mathrm{H}$ Pub.

Weinstein, C. E., Zimmermann, S. A., \& Palmer, D. R. (1988). Assessing Learning Strategies: The Design and Development Of The Lassi. In C. E. Weinstein, E. T. Goetz \& P. A. Alexander (Eds.), Learning and Study Strategies: issues in assessment, instruction, and evaluation (pp. 25-40). San Diego, California 92101: Academic Press, Inc.

Woolfolk, A., Hughes, M., \& Walkup, V. (2008). Psychology in Education. Madrid: Pearson Education Limited.

Yip, M. C. W. (2013). The Reliability and Validity of the Chinese Version of the Learning and Study Strategies Inventory (LASSI-C). Journal of Psychoeducational Assessment, 31(4), 396-403. https://doi.org/10.1177/0734282912452835 